\title{
"Nos e fidju la di gueto, nos e fidju di imigranti, fidju di Kabu Verdi": estética, antirracismo e engajamentos no rap crioulo em Portugal*
}

\author{
Otávio Raposo (https://orcid.org/0000-0001-8000-6901)' \\ Instituto Universitário de Lisboa, Lisboa, Portugal. \\ Pedro Varela (https://orcid.org/0000-0002-7332-8635)" \\ Universidade de Coimbra, Coimbra, Portugal. \\ José Alberto Simões (https://orcid.org/0000-0003-1328-5255)"II \\ Departamento de Sociologia, Universidade Nova de Lisboa, Lisboa, Portugal. \\ Ricardo Campos (https://orcid.org/0000-0003-4689-0144) IV $^{\mathrm{V}}$ \\ Faculdade de Ciências Sociais e Humanas, Centro Interdisciplinar de Ciências \\ Sociais, Universidade Nova de Lisboa, Lisboa, Portugal.
}

Resumo: Ao longo de décadas, o rap tem sido central na construção de um discurso antirracista em Portugal. Com músicas a denunciar a violência policial, a exclusão social, o legado colonial e o racismo, os rappers negros das periferias de Lisboa desempenham um papel de vanguarda na luta contra a opressão racial, particularmente aqueles que cantam em crioulo cabo-verdiano. Apoiados por dispositivos e redes digitais, estes jovens constroem circuitos de sociabilidade e de produção musical impulsionadores de uma estética insurgente capaz de desafiar o estatuto de subalternidade que lhes é imposto. O presente trabalho debruça-se sobre a importância do rap na exposição do problema do racismo na sociedade portuguesa. Recorrendo a diferentes pesquisas de natureza qualitativa, analisamos os estilos de vida, as letras de música, o acesso às redes digitais e os engajamentos dos rappers no movimento antirracista.

Palavras-chave: Rap crioulo. Jovens negros. Racismo. Estética. Portugal.

\section{"We are sons of the ghetto, we are sons of immigrants, sons of Cape Verde": aesthetics, anti-racism, and engagements in Creole rap in Portugal}

Abstract: Throughout decades, rap music has been central to the construction of an anti-racist discourse in Portugal. With songs denouncing police violence, social exclusion, colonial legacy and racism, black rappers from the peripheries of Lisbon play a vanguard role in the fight against
Recebido: 09.07.20 Aprovado: 22.10 .20

\footnotetext{
* Em português: "Nós somos filhos lá do gueto, nós somos filhos de imigrantes, filhos de Cabo Verde". Karlon \& Primeiro G-110 ilha, 2018. Este texto inscrevese nos projetos ArtCitizenship (PTDC/SOCSOC/28655/2017) e "UIDB/04647/2020" do CICS. NOVA - Centro Interdisciplinar de Ciências Sociais da Universidade Nova de Lisboa, ambos financiados por fundos nacionais através da Fundação para a Ciência e a Tecnologia (FCT), I.P. Resulta ainda do apoio da FCT, no âmbito da bolsa de Doutoramento SFRH/ BD/129171/2017.
}

I. Otávio Raposo
é pesquisador
integrado do Centro
de Investigação
e Estudos de
Sociologia (Cies-
Iscte) e professor
auxiliar convidado
do Instituto
Universitário de
Lisboa (ISCTE-IUL),
Lisboa, Portugal. .
<otavio_raposo@
iscte-iul.pt>.

I. Otávio Raposo é pesquisador integrado do Centro de Investigação e Estudos de Sociologia (CiesIscte) e professor auxiliar convidado do Instituto Universitário de Lisboa (ISCTE-IUL), <otavio_raposo@ iscte-iul.pt>. 
II. Pedro Varela é mestre em antropologia e doutorando no Centro de Estudos Sociais, Universidade de Coimbra, Portugal. <pedromfvarela@ gmail.com>.

III. José Alberto Simões é professor auxiliar no

Departamento de Sociologia da Universidade Nova de Lisboa (NOVA FCSH), pesquisador no Centro Interdisciplinar de Ciências Sociais (CICS.NOVA - NOVA FCSH), Lisboa, Portugal. <sjav@fcsh.unl.pt>

IV. Ricardo Campos é mestre em sociologia e doutor em antropologia visual, investigador integrado (Investigador FCT) no CISC.NOVA, Universidade Nova de Lisboa, Faculdade de Ciências Sociais e Humanas, Centro Interdisciplinar de Ciências Sociais, Lisboa, Portugal. <rmocampos@ yahoo.com.br>

1. O rap crioulo em Portugal distinguese por ser cantado em crioulo caboverdiano. Esta é a língua dominante de Cabo Verde, uma combinação híbrida entre o português e outras línguas da África Ocidental. Existem diversos crioulos de base portuguesa, nomeadamente o crioulo da GuinéBissau, próximo do racial oppression, particularly those who sing in Cape Verdean Creole. Supported by digital devices and networks, these young people build circuits of sociability and musical production that promote an insurgent aesthetic capable of challenging their imposed subordinated status. This paper focuses on the relevance of rap in making the problem of racism visible in the Portuguese society. Using different qualitative researches, we analyzed lifestyles, lyrics, access to digital networks and the engagements of rappers in the anti-racist movement.

Keywords: Creole rap. Black youth. Racism. Aesthetics. Portugal.

\section{Introdução}

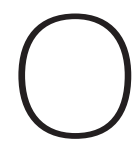
presente artigo parte do rap protagonizado pelos jovens negros das periferias de Lisboa, nomeadamente do rap crioulo ${ }^{1}$, para refletir sobre a produção musical, os estilos de vida e o antirracismo em Portugal. Com cada vez mais adeptos, este estilo musical desafia a posição de subalternidade ocupada pelos afrodescendentes na sociedade portuguesa, ao denunciar o racismo e a criminalização dos territórios em que vivem. A maioria desses rappers nasceram e/ou foram socializados em Portugal, pertencem às classes populares, vivem em bairros rotulados como "problemáticos" às margens de Lisboa e são descendentes de famílias oriundas de países africanos que foram outrora colônias portuguesas, principalmente de Cabo Verde. Por via das suas letras musicais, estes rappers contrariam a imagem benevolente de um Portugal multicultural, tolerante e livre de discriminação incentivada pelos discursos oficiais, confrontando criticamente o legado do colonialismo e a sua conexão com processos mais amplos de exclusão. O racismo cotidiano e a estigmatização a que são sujeitos reafirmam a sua exclusão do "corpo da nação", pensada a partir do ideário da branquitude², o que para alguns deles se conjuga com o agravante de lhes ter sido negada a nacionalidade portuguesa. O princípio de jus sanguinis, pelo qual se rege a lei atual, converte-os muitas vezes em estrangeiros no seu próprio país ${ }^{3}$, legitimando o caráter outsider destes jovens, sobretudo quando se acumulam com outros elementos de marginalização: pobreza, baixa escolaridade, estigma e segregação territorial.

A poesia em crioulo e em português ${ }^{4}$ é a matéria-prima para reinventarem a vida e imaginarem a si próprios de uma forma digna, na qual redes digitais e de sociabilidades se tornaram importantes aliadas. Mais do que uma mera atividade lúdica, a música rap para esses jovens exerce uma função contraestigmatizadora, fomentando identidades positivas ao mesmo tempo que incute projetos de transformação social. Com um discurso consciente e de valorização da negritude, esses rappers afirmam uma estética insurgente que enaltece áreas marginalizadas da cidade ao mesmo tempo que tornam visível uma presença negra e africana que tarda em ser reconhecida pelas instituições do Estado. Ao propor o conceito de 
"estética insurgente", chamamos atenção para o potencial das práticas criativas entre os sujeitos racializados (Raposo, Sedano \& Lima, 2020), em que a cidadania, a pertença e o território são questionados com vista a afirmar um espaço de legitimidade na sociedade portuguesa.

Neste artigo articulamos pesquisas de natureza qualitativa, realizadas pelos autores em diferentes períodos de tempo, envolvendo etnografia, observação on-line e antropologia visual. A realização do documentário Nu Bai. O rap negro de Lisboa ${ }^{5}$ (2007) foi decisivo para a familiarização de alguns de nós com o rap crioulo e a condição juvenil das populações afrodescendentes. Este conhecimento solidificou-se a partir do trabalho de campo realizado na Cova da Moura (Raposo, 2005; Varela, Raposo \& Ferro, 2018) e Arrentela (Raposo, 2007), bairros com forte presença negra, localizados nas cidades da Amadora e do Seixal, municípios limítrofes à cidade de Lisboa. Outra parte da observação empírica resultou de duas pesquisas financiadas, sendo a primeira sobre o movimento hip-hop em Portugal (2002-2004) e a segunda (2010-2011) incidindo sobre o papel desempenhado pela internet e outros recursos digitais nas práticas de produção/consumo do rap (Simões \& Campos, 2017). As entrevistas e reflexões desse capítulo alimentam-se principalmente do material analítico proveniente desses projetos realizados e de outros em andamento e/ou atualização.

\section{Localizando o rap e a cultura hip-hop: das ruas de Nova lorque aos circuitos digitais}

O rap (acrônimo de rhythm and poetry), apesar de se ter difundido por todo o planeta como gênero musical multifacetado, composto por diversos subgêneros, tem já uma história razoavelmente longa de cerca de meio século. É unânime a identificação espaço-temporal de suas origens: Nova lorque, início dos anos 70 do século $X X$. Foi no South Bronx que despontou a denominada cultura hip-hop ${ }^{6}$, uma cultura de rua essencialmente juvenil, composta por diferentes vertentes expressivas - rap (djing e mcing), graffiti e break dance (Bennett, 2000; Keyes, 2004; Rose, 1994). A vertente musical - o rap - é composta a partir de dois elementos expressivos e dois agentes criativos: o djing (atividade levada a cabo pelo disk jockey) e o mcing (atividade a cargo do mestre de cerimônias ou cantor rap) ${ }^{7}$.

Podemos identificar no rap, desde as suas origens, uma dimensão política que se converteu em símbolo do próprio movimento (Lipsitz, 1994; Rose, 1994). Numa certa acepção, desde os seus primórdios, o hip-hop e o rap constituíram-se como formas de expressar o descontentamento e a resistência de populações racializadas que vivem em contextos de pobreza e segregação urbana (Kitwana, 2004; Neal, cabo-verdiano. No entanto, ao longo do texto quando nos referirmos ao rap crioulo, ou à língua crioula, estaremos nomeando apenas a matriz caboverdiana, dada a sua maior influência no rap e na linguagem quotidiana dos jovens das periferias de Lisboa.

2. A ideia de 'raça', com os seus fenótipos associados, tem servido como matriz no estabelecimento de critérios para designar aqueles que pertencem ao corpo da nação e quais são os seus estrangeiros, ocupando um papel central no projeto moderno de edificação do Estadonação (Goldberg, 2002).

3. A Lei da Nacionalidade em Portugal fundamentada na prevalência do princípio de jus sanguinis sobre o princípio de jus soli, determina que não basta nascer em Portugal para se ser português. Para mais informações consultar: <http:// www.pgdlisboa. pt/leis/lei_ mostra_articulado. php?nid=614 \&tabela=|eis $>$

4. Embora o foco deste artigo seja o rap crioulo, consideramos que seria equivocado não ampliar a análise para o conjunto de rappers negros das periferias de Lisboa. Independentemente 
da língua, todos partilham condições sociais e econômicas bastante parecidas e fazem parte de uma mesma história: a diáspora africana. Nessa perspectiva, uma das componentes fundamentais na formulação das identidades desses rappers é sua condição de pobres e negros, bem como o conteúdo politizado de suas letras, o que torna as diferenças de nacionalidade (e linguística) pouco significativas. Por outro lado, a maioria dos rappers que cantam em crioulo também rimam em português, existindo também vários casos de jovens brancos ou de outras origens africanas a utilizarem o crioulo em suas músicas (Raposo, 2007).

5. Este documentário foi filmado entre os anos 2003 e 2006, um registo audiovisual extremamente rico na abordagem de uma expressão musical até então marginalizada.

\section{A este respeito importa referir à figura lendária de Afrika Bambaata, fundador de uma organização informal juvenil intitulada The Zulu Nation, criada com o intuito de canalizar as tensões locais para a música, a dança e o grafite, dando origem ao hip-hop.}

7. A partir da base
2004; Simões, 2010). Desta forma, o rap procurava refletir a experiência de marginalização, exclusão social e racismo vivida nos bairros pobres de Nova lorque.

As palavras dos rappers geralmente narravam histórias do cotidiano sob forma rimada que tanto podia ser de ordem política e social, como sexual (Rose, 1994; Perkins, 1996), apresentadas em contextos de improviso onde a destreza verbal era avaliada em combates simbólicos (conhecidos por battles) entre os participantes. Aquilo que começou por ser um fenômeno localizado, rapidamente se expandiu, fortemente impulsionado pela mídia e pelas indústrias culturais: indústria discográfica, televisiva e cinematográfica. Hoje estamos diante de um fenômeno global, o que significa que, apesar da matriz original do hip-hop e do rap ainda existir, multiplicaram-se os formatos expressivos e os subgêneros musicais enquadrados nesta categoria. Podemos certamente afirmar que o rap se adapta a novos contextos sociais, culturais e econômicos, transformando-se num gênero musical cada vez mais híbrido (Huq, 2006; Pardue, 2011; Saucier, 2011). Neste sentido, ainda que seja possível detectar convergências entre todas as suas expressões, por partilharem um imaginário e referências simbólicas comuns, encontramos igualmente divergência entre as suas diferentes manifestações que decorre das especificidades dos contextos onde o hip-hop e a música rap foram adotados e se implantaram, adaptando e recriando localmente a linguagem globalmente partilhada (Simões, 2010: 70; Mitchell, 2001).

A anterior matriz identitária do rap, relacionada às origens sociais específicas e a uma vocação contestatária, evidenciam um vínculo ideológico que ainda hoje permanece como imagem de marca deste movimento cultural. Há, por isso, uma corrente do rap - com menor visibilidade quando comparada com o rap "comercial" (Simões, 2010) - que continua a afirmar a sua ligação ao local, às culturas de rua e a um propósito de denúncia social e política (Fradique, 2003; Raposo, 2010).

O rap, enquanto voz dos oprimidos, continua, atualmente, a expressar-se nos mais variados recantos do planeta, sendo empregue por diversas comunidades como canal de afirmação na esfera pública (Huq, 2006; Mitchell, 2001; Pardue, 2011; Saucier, 2011). Na verdade, esta vocação contestatária do rap decorre das afinidades entre os contextos sociais onde este surgiu e posteriormente se implantou, onde se podem identificar circunstâncias e causas próximas.

Deste modo, embora sejam conhecidas as semelhanças socioeconômicas e étnicas existentes entre os contextos criativos da música rap em vários países europeus associados principalmente, embora não inteiramente, a populações migrantes de origem africana, latina e asiática -, bem como entre a juventude urbana norte-ameri- 
cana (pelo menos parte dela) que se dedica às mesmas práticas (Mitchell, 2001; Bennett, 2000), são igualmente óbvios os elementos específicos, patentes, desde logo, na utilização das rimas e do vernáculo próprios de cada país, marcados por preocupações localmente significativas. Do mesmo modo, podemos identificar um paralelismo entre os dois contextos no que diz respeito às funções preenchidas pela música rap enquanto veículo de protesto político, ideológico ou racial (Bennett, 2000).

Um dos casos mais flagrantes em que isso acontece remete para a sua apropriação por parte de populações racializadas e jovens migrantes ou descendentes de migrantes. Da juventude negra da periferia de Lisboa (Campos \& Simões, 2011; Fradique, 2003; Raposo, 2007; 2010; Simões, Nunes \& Campos, 2005) aos jovens dos subúrbios franceses (Huq, 2006), passando pelos jovens turcos na Alemanha (Bennett, 2000; Weller, 2000) ou pelos jovens afrodescendentes no Brasil (Dayrell, 2005; Macedo, 2015; Pardue, 2011), vários são os casos relatados pela literatura em que o rap se torna um instrumento de denúncia e combate à discriminação, ao racismo e à precariedade das condições de vida. Neste sentido, ainda que as causas de contestação se possam alterar de acordo com os contextos de implantação da música rap, os temas de discriminação social e racial (mesmo que relacionados a diferentes grupos) mantêm a sua relevância, mostrando que uma parte significativa do rap atual permanece um gênero social e reivindicativo por excelência. Essas reivindicações são, porém, mais notórias em determinados países e contextos geográficos, como acontece no caso dos grandes centros urbanos do Brasil, onde a discussão em torno da negritude se cruza com o gênero, a origem social e o território privilegiado de atuação dos rappers, as periferias (Dayrell, 2005; Macedo, 2015; Pardue, 2011).

Uma das transformações mais evidentes na forma como o rap de natureza mais politizada e, nalguns casos semiamadora, tem sido produzido e consumido, está relacionada com a crescente democratização do acesso à internet e aos dispositivos digitais (Simões \& Campos, 2017). Esta questão tem alimentado uma nova linha de pesquisa que revela o impacto que as mídia digitais têm tido num conjunto de culturas urbanas e juvenis de natureza mais alternativa ou amadora (Hodkinson, 2004; Woods, 2020; Campos, 2020). O fato é que esses canais abriram novas oportunidades não apenas para a produção musical e videográfica, mas essencialmente para a sua difusão, alargando os circuitos geográficos de consumo deste gênero musical que marca uma presença relevante na esfera pública digital (Yúdice, 2007; Aderaldo \& Raposo, 2016; Marcon, Sedano \& Raposo, 2018).

Neste sentido, podemos examinar os circuitos digitais de produção e consumo do rap através da forma como ampliam as redes de difusão existentes fora da inter- musical fornecida pelo DJ, atua o MC, acrescentando a vocalidade e o texto, geralmente recorrendo ao improviso, o denominado freestyling. 
8. A vinda de africanos negros para Portugal na época moderna remonta ao século $X V$, uma presença que influenciou desde o vocabulário e a religião à literatura, música e toponímia das cidades. Estimase que entre os séculos XVII e XVIII cerca de $15 \%$ da população de Lisboa fossem de mulheres e homens negros (Lahon, 2004).

\section{Como uma} parte significativa desses imigrantes adquiriram nacionalidade portuguesa, desaparecendo das estatísticas oficiais enquanto imigrantes, este número acaba por subdimensionar a presença de africanos a viver em Portugal. Só no ano de 2019, por exemplo, mais de 13 mil africanos adquiriram a nacionalidade portuguesa (SEF, 2019).

10. Expressão utilizada para designar sociabilidades de rua, em contexto urbano, associadas sobretudo a grupos juvenis, principalmente do sexo masculino. Nos estudos clássicos sobre a juventude, estes grupos apresentam um carácter "desviante" ("corner boys") por contraste com grupos estudantis de classe média ("college boys"). Ver, por exemplo, Whyte (2005). net, contribuindo para edificar novos canais de propagação e partilha deste gênero musical. Podemos dizer que as ferramentas digitais - da internet a uma panóplia de equipamentos tecnológicos de uso pessoal - se apresentam como recursos que intervêm na produção deste campo cultural, fazendo parte do mesmo. Por outro lado, pelas suas próprias características, permitem tornar acessível a um público não especialista um conjunto de ferramentas de criação e difusão cultural, edificando um circuito próprio e alternativo de disponibilização dos produtos gerados, à margem de canais profissionais de disseminação, controlados pela indústria discográfica e pelos mídia tradicionais. É neste sentido também que podemos sublinhar a importância destas ferramentas na reconfiguração do papel de agência dos seus utilizadores, fomentando a sua visibilidade no espaço público (Campos \& Simões, 2011; Simões \& Campos, 2017). Este é o caso do rap crioulo, cujas oportunidades oferecidas pelas ferramentas digitais foram determinantes na ampliação de sua influência na cultura hip-hop, transformando-se num expoente de resistência e insurgência da juventude negra em Portugal tanto nas ruas como no ciberespaço.

\section{Situando os rappers negros de Lisboa}

A migração laboral africana para Portugal teve início nos anos 1960, ainda no quadro colonial, com uma intensificação nas décadas de 1970 e 1980, após a libertação dos territórios colonizados, em que se destaca a vinda de imigrantes cabo-verdianos (Varela, Raposo \& Ferro, 2018) ${ }^{8}$. Concentrada na região metropolitana de Lisboa, onde vive $82 \%$ da sua população (Oliveira \& Gomes, 2017), existem oficialmente 103.346 africanos residentes em Portugal, dos quais 37.436 têm nacionalidade cabo-verdiana, segundo os dados mais recentes (SEF, 2019) ${ }^{9}$.

Os processos de migração, negociação e reterritorialização de identidades transnacionais e diaspóricas em Portugal propiciaram sociabilidades cotidianas marcadamente híbridas e cosmopolitas entre os seus agentes. O crioulo é exemplar dessas dinâmicas, dado este idioma estender-se para além da comunidade cabo-verdiana, transformando-se na língua franca de muitos jovens das periferias de Lisboa. Assim, entre aqueles que partilham a sociabilidade de esquina ${ }^{10}$ e o estilo rap, não é incomum ouvir esta língua entre jovens brancos e negros de outras origens, principalmente nos bairros com forte presença negra (Raposo, 2010). Tal fenômeno já era apontado pelo DJ Sas há mais de dez anos atrás:

O rap comunica de bairro em bairro, e em qualquer bairro se fala
crioulo. Eu não conheço um bairro, sobretudo na zona de Lisboa,
diz-me lá o bairro que não fala em crioulo?! Diz-me um! Eu não
conheço, eu não os conheço todos, mas todos os bairros que eu já
fui, toda a gente falava crioulo. Até os pulas [brancos] boy! Até os 
pulas percebem e sabem falar, tás a ver a dica (Nu Bai. O rap negro de Lisboa, 2007).

O crioulo assume-se, assim, como a língua da street por excelência dos jovens das periferias da capital portuguesa. Contudo, este crioulo apresenta diferenças consideráveis em relação ao que é falado pelos "mais velhos", pois está influenciado pela fonética portuguesa, estando também carregado com expressões trazidas de outras partes do mundo: Estados Unidos, Angola e Brasil. Estas mudanças geracionais também se revelam no campo das estéticas, identidades e projetos de futuro. Ao serem socializados num contexto urbano europeu, em que os próprios agentes de socialização estão em mutação, essa juventude não reproduz mecanicamente as referências étnicas e os estilos de vida de suas famílias em Portugal, confrontando-se com uma cultura já "filtrada", reinterpretada em variados aspetos e imbuída de elementos da cultura portuguesa (Raposo, 2007), criando assim novas formas de estar na vida e de se expressar.

Não é só a especificidade da língua que distingue o rap crioulo em Portugal. As componentes de resistência e conscientização em suas letras aproxima-o das vertentes de rap mais politizado e consciente, o que também expressa o contexto desfavorecido de seus intervenientes. Cantado em sua grande maioria por descendentes de cabo-verdianos de bairros socialmente precarizados, essa juventude está mais exposta aos efeitos da pobreza, do desemprego, da violência policial, do estigma territorial e do racismo. Por isso, rimar em crioulo para muitos deles é como se fosse um "grito de liberdade" diante de uma marginalização que os priva do direito à palavra e da perspectiva de um futuro digno, permitindo um espaço comunicacional sem precedente. Foi o que afirmou Chullage no documentário Nu Bai. O rap negro de Lisboa (2007):

Tu no telejornal ou na televisão não tens espaço para te exprimir, não tinhas nenhum espaço. E o rap criou um espaço que trazia isso tudo. O rap informava o people no bairro, educava o people, tás a ver, e ao mesmo tempo entretinha o people. [...] E o rap em crioulo mantém... A maioria dos rappers cabo-verdianos de Portugal mantém aquela mensagem social, de conscientização. Então quando isto ainda vem em crioulo é quase que um grito de guerra, um grito de liberdade!

Mesmo não havendo estatísticas oficiais de cariz étnico-racial sobre as populações negras em Portugal ${ }^{11}$, pesquisas recentes revelam sinais de desigualdade no mercado de trabalho, na educação e no acesso à Justiça ${ }^{12}$.

Se os aspectos socioeconômicos e a origem imigrante são fatores preponderantes para compreendermos as razões pelas quais as populações negras ocupam

11. O Estado português não faz recolha de dados étnico-raciais apesar de isso ser recomendado por diversos relatórios internacionais, sendo uma exigência do movimento negro e antirracista.

12. Um exemplo é a desigualdade na educação que se manifesta entre as crianças de nacionalidade africana, cuja taxa de reprovação é três vezes superior no primeiro ciclo do que as crianças de nacionalidade portuguesa (Abrantes \& Roldão, 2016). Para uma visão mais ampla sobre as desigualdades que afetam as populações afrodescendentes, ver: Raposo et alii (2019). 
13. Oliveira Salazar foi um ditador português que liderou o mais longo regime fascista da Europa, tendo a ditadura sido prolongada até a Revolução de 25 abril de 1974. Cavaco Silva é um político de direita que foi primeiroministro (1985-1995) e presidente da república portuguesa (2005-2015); e o 10 de junho é o feriado do Dia de Portugal que é celebrado frequentemente pela extrema-direita.

\section{Lançado} em 1994, esta compilação foi um marco para o rap em Portugal, levando um estilo ainda desconhecido ao grande público para a ribalta. posições pouco prestigiadas na sociedade portuguesa, não menos importante é considerar os efeitos do racismo institucional e de sua relação com territórios segregados (Raposo et alii, 2019). Nos últimos anos, diversos relatórios internacionais têm alertado para um problema estrutural de racismo em Portugal, nomeadamente a brutalidade policial contra negros (Amnistia Internacional, 2018; Ecri, 2018).

\section{"Portukkkal é um erro": música rap e movimento antirracista}

O debate sobre o racismo nas esferas institucionais e mediáticas portuguesas tem adquirido uma forte relevância nos últimos anos, ofuscando a narrativa luso-tropicalista produtora de um imaginário de nação que higieniza os processos de violência que acompanharam o passado colonial. Esse discurso ideológico não apenas interpreta o colonialismo português a partir de um excepcionalismo cultural e moral (Vale de Almeida, 2000), como desconsidera o fenômeno do racismo na sociedade portuguesa na atualidade, entendendo-o enquanto prática individual e excecional, ao invés de um problema estrutural e institucional (Araújo \& Maeso, 2016; Raposo et alii, 2019). Contudo, desde a década de 1990, os rappers negros das periferias de Lisboa denunciam o racismo estrutural no país, incentivando uma visão antirracista na mídia, no movimento associativo e na vida cotidiana. Esses artistas foram um dos principais responsáveis por levar o tema do racismo para o debate público em Portugal, ao rimarem experiências de injustiça sentidas na "primeira pessoa", tais como violência policial, estigma territorial, discriminação racial e pobreza. Um dos precursores foi General D, cujo single "Portukkkal é um erro", de 1994, dizia o seguinte:

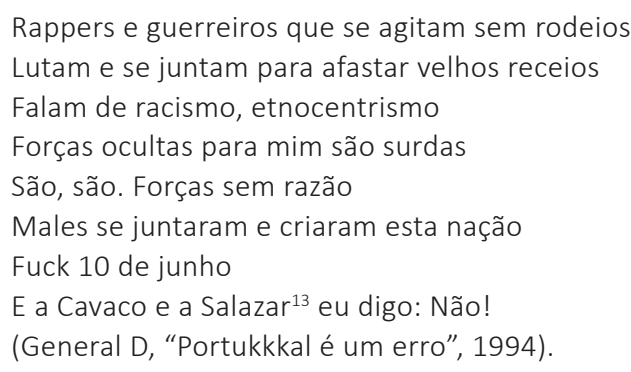

No mesmo ano, o grupo Zona Dread, no pioneiro álbum "rapública"14, cantava:

\section{Só queremos ser iguais}

Nem sermos menos, nem ser mais

Só queremos ser iguais

Vamos lá, logo ao assunto

Não é o momento de começar a história no estilo lento 
O racismo está nas ruas de Lisboa

E o governo finge que tudo está na boa

Mas que se lixe o governo

(Zona Dread, "rapública”, 1994).

Situarmos o contexto político em que se dá a afirmação do rap português ajuda-nos a compreender o papel dos rappers afrodescendentes na manifestação do racismo em Portugal. Se o final da década de 1980 assinalou a emergência deste estilo musical (Contador 2001; Fradique, 2003; Simões, 2010; 2018), os anos de 1994-1995 marcaram o boom do rap no país, quando o estilo foi difundido para um público mais amplo ${ }^{15}$. Este alargamento da influência do rap não passou desapercebido pelo poder público. Pelo contrário, sua incorporação à cultura mainstream portuguesa fez com que os dois principais candidatos às eleições presidenciais de 1996, Jorge Sampaio e Cavaco Silva, o utilizassem como música de campanha eleitoral (Fradique, 2003). Paralelamente, este período de afirmação do rap português coincidiu com a ascensão de grupos de extrema-direita que faziam ataques violentos contra populações negras e imigrantes, além de militantes de esquerda ${ }^{16}$. Perante a maior expressão desses grupos na sociedade, emergiu pela primeira vez em Portugal um movimento associativo antirracista, cujas ligações ao rap até hoje mantêm-se presentes ${ }^{17}$. A associação SOS Racismo ${ }^{18}$ foi exemplar nessa conexão entre movimento antirracista e música rap. Essa aliança se deu já nos primeiros anos de existência do movimento, e contou com a participação de vários rappers, entre os quais General D e Ermelindo (aka Lord Strike). Nessa fase embrionária do movimento antirracista em Portugal tais rappers, bem como outros como os Family ou o grupo feminino Djamal, colaboraram com essas associações antirracistas em shows e outras atividades de combate ao racismo ${ }^{19}$. José Falcão, dirigente e fundador do SOS Racismo, uma das primeiras associações antirracistas em Portugal, revela essa ligação:

O General D aparece no início do SOS Racismo, em 1991. Ele vem ter conosco a dizer que queria fazer uma homenagem ao Malcom $X$ no contexto da sua morte. E, a partir daí começamos a estar sempre com ele. Ele não era muito de ir a reuniões. Mas a malta estava sempre muito junta. [...] O Lord Strike [Ermelindo] na altura fazia parte de um grupo [de rap] [...] fazíamos atividades com eles, sobretudo com o Lord Strike que era o gajo mais próximo (José Falcão, entrevista, 2020).

Na década seguinte, vários rappers tiveram um papel de destaque na criação de associações de bairro e coletivos antirracistas, ajudando a sedimentar as bases daquilo que viria a ser o movimento negro em Portugal. A Associação Cultural de Jovens Afrodescendentes (Khapaz), criada no ano 2000, é um caso paradigmático, pois as
15. Em 1994 e 1995

foram editados os primeiros álbuns gravados no país, destacando-se vários artistas como General D, Da Weasel, Black Company, Ithaka e Mind da Gap; e, através da coletânea rapública, Boss AC, Black Company, Family, Funky D, Líderes da Nova Mensagem, New Tribe e Zona Dread. Em 1996 foi lançado o álbum de Djoek, quase todo cantado em crioulo; e em 1997 foi gravada uma das primeiras bandas femininas em Portugal: Djamal.

16. Em 1989, José Carvalho, operário fabril e militante do Partido Socialista Revolucionário (PSR), foi assassinado por skinheads fascistas E, em 1995, no Dia de Portugal, um grupo de extremadireita espancou até à morte o jovem negro Alcindo Monteiro.

17. Nos anos 1990 surgiram em Portugal diversas organizações antirracistas como o SOS Racismo, Frente Anti-Racista e Movimento Anti-Racista, dando centralidade a uma luta que o associativismo imigrante não era capaz de dar.

18. Para maiores informações, ver em: <https://www. sosracismo.pt/>. 
19. Destacam-se vários eventos antirracistas com presença de música rap nos anos 1990’s como o “Dia Internacional Contra o Racismo"; "Festa de Todas as Cores"; "Concerto Contra a Discriminação Racial e Xenofobia"; ou Gala "Todos diferentes, todos iguais".

20. Na década de 1990 assistiu-se a uma crescente estigmatização dos jovens negros pela agenda midiática e política, cuja imagem passou a estar associada às gangues e aos comportamentos violentos. Tais estereótipos ganharam um pretenso estatuto científico através do termo "segunda geração de imigrantes", que se serve das referências culturais dos seus progenitores para legitimar a sua suposta não integração na sociedade portuguesa e delimitar um conjunto de problemas sociais (Raposo, 2005; 2007).

\footnotetext{
21. Para maiores informações, ver em: <https:// plataformagueto. wordpress.com/>.

22. Atualmente, a grande maioria das lideranças associativas antirracistas são negras, uma realidade distinta do
}

suas ações, dinamizadas em grande parte por rappers, contrapunham-se às visões estigmatizantes que culpabilizavam os jovens negros da periferia por um suposto aumento da violência urbana, contribuindo para o redesenhar de uma agenda antirracista no país com foco na malvista "segunda geração de imigrantes" 20 (Raposo, 2007). Localizada no bairro da Arrentela (cidade do Seixal), essa associação fazia do rap (e do hip-hop) o seu principal repertório de denúncia ao racismo estrutural (e a outras injustiças) a que eram expostos quotidianamente, tendo construído um estúdio para apoiar a criação musical dos seus associados (Raposo, 2007; 2019). Um de seus membros fundadores é o rapper Chullage, que descreve da seguinte forma a importância do hip-hop para essa associação:

\begin{abstract}
Hip-hop está a construir bueda cenas [muitas coisas], o hip-hop construiu essa associação, onde nós queremos através do hip-hop conscientizar as pessoas. Hip-hoppers vem aqui ler, vem aqui estudar, mobilizam-se aqui, ouvem música em comum, discutem problemas e partem para a ação (Nu Bai. O rap negro de Lisboa, 2007).
\end{abstract}

Ponto de referência para jovens de diferentes bairros que partilhavam uma visão do rap enquanto música de conscientização e valorização da negritude, com forte influência do rap crioulo, a associação Khapaz fomentou nalguns deles projetos mais radicalizados de luta contra o racismo. Um deles foi a criação do Jornal Gueto: Olhos, Ouvidos e Vozes em 2007, que mais tarde levaria a constituição da Plataforma Gueto ${ }^{21}$. A experiência de organizar jovens de diferentes bairros da periferia de Lisboa em torno de uma fanzine para combater o racismo e outras injustiças teve um importante impacto no modus operandi da luta antirracista no país. Até então, os jovens negros da periferia exerciam na maioria das vezes um papel secundário nas dinâmicas do movimento antirracista em Portugal22. Não por acaso, a exigência para que suas vozes fossem ouvidas pela sociedade portuguesa aparece em relevo no editorial de lançamento do jornal:

Racismo, desemprego, falta de oportunidades ou violência policial fazem parte do cotidiano de milhares de jovens dos subúrbios de Lisboa. Conosco não é diferente. A nossa voz não é ouvida, os nossos problemas esquecidos e as nossas vivências caricaturadas ou estigmatizadas. Por isso, é urgente criarmos associações, colectivos informais e jornais que expressem as nossas ideias e opiniões para colocar na cena pública os nossos anseios e reivindicações. (...) Chega de ser apenas os média e as instituições políticas os produtores de informações, geralmente deturpadas, sobre o gueto. Os jovens dos guetos querem falar pela sua própria voz para exigir direitos e uma melhor qualidade de vida. Exigimos a nacionalidade para todos os que nasçam em território português! Legalização 
de todos os imigrantes! Defendemos o ensino da história africana nas escolas com grande número de afrodescendentes! Fim da violência policial! Igualdade de oportunidades!" (Editorial, Jornal Gueto, n. 0, 2007).

Vários rappers afrodescendentes tiveram um papel determinante na criação deste jornal, nomeadamente aqueles que cantavam em crioulo.

O forte cunho ideológico e político do rap crioulo está presente desde a origem deste estilo musical, que se confunde com a emergência do estilo rap em Portugal. Isto porque desde o início surgem músicas cantadas em português, inglês e crioulo. Se até a década de 1990, o rap crioulo desenvolvia-se principalmente fora do mercado discográfico ${ }^{23}$, nomeadamente nas ruas dos bairros periféricos de Lisboa, após a passagem do novo milênio este estilo tomou uma maior dimensão, com vários artistas lançando álbuns e mixtapes. Acompanhavam os primeiros passos de uma transformação das tecnologias de criação musical que facilitaram o impulsionar de projetos musicais autônomos, e que deram origem a um circuito de rap underground de produção, divulgação e consumo assente numa lógica do it yourself.

Os primeiros anos de 2000 foram céleres no surgimento de vários trabalhos gravados, entre os quais Da Blazz, do Casal de São José (Mem Martins), Nigga Poison e TWA, da Pedreira dos Húngaros; ou Chullage, da Arrentela. Os rappers desses bairros periféricos, em conjunto com outros da Cova da Moura, do Casal da Boba (Amadora), do Miratejo (Seixal) ou do Monte da Caparica (Almada), apenas para citar alguns, desempenharam um papel central no amadurecimento de um rap crioulo, cujas sinergias e senso de pertença lhes facultaram as características de um movimento urbano. Isso porque as afinidades musicais, estéticas e de estilos de vida em torno do rap e de vivências em comum permitiram a criação de um circuito de sociabilidade e de criação artística produtora de vínculos identitários e sentidos de vida. Ao narrar as suas experiências de margem - ligadas aos processos migratórios, à vivência em bairros segregados, ao realojamento forçado, à pobreza ou ao racismo - através da poesia em crioulo, eles forjaram uma identidade coletiva que serve de "abrigo virtual" num meio marcado por situações adversas (Agier, 2001: 8). Tais características estão bem presentes na música “Dedicaçon” (2001), do grupo Nigga Poison:

Esta música aqui é dedicada para todos os pretos do gueto que são puros real niggas para aqueles que já sofreram porque são pretos

Oh Miraflor, Yo

Oh Ghetto G, Yo período em análise. E ultimamente tem se fortalecido um movimento negro em Portugal através da construção de diversos coletivos, grande parte deles liderados por mulheres negras. Foi a partir de 2014 que se assistiu a um crescimento exponencial de associações e coletivos negros antirracistas, entre os quais Femafro (<https://femafro. pt>), Consciência Negra (<https:// www.facebook. com/pg/lutanegra/ posts>), Djass Associação de Afrodescendentes (<https://www. facebook.com/ associacao.djass $>$ ), AfroLis (<https:// radioafrolis.com $>$ ), Inmune - Instituto da Mulher Negra em Portugal (<https:// www.facebook. com/INMUNE. PORTUGAL>), configurando aquilo que hoje é o movimento negro em Portugal. Este movimento tem mobilizado protestos e um debate público de forma inédita no país. Não é o objetivo do artigo abordar esta época mais contemporânea, mas refletir sobre o papel dos rappers negros no impulsionar de um conjunto de coletivos e associações que ajudaram a estruturar esse movimento.

23. As primeiras gravações de rap em crioulo em Portugal 
foram feitas a partir de 1994 por Family, Zona Dread e Boss AC, bem como por Djoek, responsável por lançar, em 1996, o primeiro álbum cantado em crioulo.

24. Tradução livre dos autores do crioulo para português. Ouvir em <https://youtube. com/watch? $\mathrm{v}=8 \mathrm{mMA}$ $9 N \vee X q 5 w>$.

\author{
Oh Ghetto Stress, Yo \\ É nossa morada, Yo \\ Entra na realidade \\ Entra no mundo de verdade \\ Completa a tua mente \\ Para veres com simplicidade \\ Nada aqui é real \\ Neste fucking chão de Portugal \\ Legal ou ilegal \\ Eles tratam-nos todos sempre igual \\ Mas o povo cabo-verdiano \\ Nunca foge das suas origens \\ Lutam pela vida \\ todos os dias que passam \\ [...] Pretos já sofreram muito \\ Pretos já sofreram muito calados \\ Lembrando o nosso passado \\ Nós fomos todos enganados [...]. \\ (Nigga Poison, Dedicaçon Original Mix, 2001) ${ }^{24}$.
}

Esta comunidade emocional em torno do rap crioulo - que se abre também ao "rap do gueto" cantado em português por jovens brancos e negros - é um espaço bastante masculinizado, a exemplo de outras culturas juvenis em Portugal e no mundo. No entanto, este estilo contou com a presença feminina desde as suas origens (J. Simões, 2013; S. Simões, 2018). Assim, destacam-se no rap crioulo feminino os trabalhos das rappers G Fema, Juana na rap ou de Mynda Guevara, uma artista da Cova Moura. Sobre a menor projeção das mulheres no movimento, Mynda Guevara refere:

O fato de ter crescido na Cova da Moura também é importante para a música que faço. O rap crioulo tinha muita força aqui. [...] O rap é um meio um pouco machista. Nós, mulheres, temos de provar constantemente que somos capazes de fazer as coisas. Temos de trabalhar a duplicar ou a triplicar em comparação com os rapazes. Já senti isso na pele, principalmente no início. É preciso muita força de vontade. (Mynda Guevara apud Duarte, 2018).

\section{Rap crioulo:}

identidade, visibilidade e engajamentos

Com um forte poder agregador, a música rap é um agente de socialização poderoso entre a juventude, criador de um espaço de autorreconhecimento que fomenta um "espírito de grupo". Para os jovens negros dos bairros periféricos de Lisboa, as características agregadoras desta linguagem são igualmente acompanhadas de experiências, valores e representações ligadas a um sentimento comum de vulne- 
rabilidade coletiva e rejeição às instituições oficiais da sociedade portuguesa. Parte significativa das rimas que compõem abordam o dia a dia de opressão nos bairros em que vivem, denunciando injustiças e projetando uma visibilidade positiva com vista a inverter o seu estatuto subalterno e ascender a uma existência valorizada.

A sensação do inóspito está bem presente em suas canções, uma condição estranhamente paradoxal quando se é considerado o "outro" no próprio país em que se nasceu. Tais contradições tendem a ser confrontadas de forma ainda mais intensa no rap crioulo, quando a recusa pelo estatuto de outsider é habilmente performatizada numa estética insurgente capaz de deslocar as disposições de poder e subverter as categorias que os desqualificam. Não por acaso alguns deles se autodeclaram como cabo-verdianos ou africanos em suas canções, num exercício de reflexão identitária que põe em manifesto o orgulho por suas origens, tantas vezes desonradas pela discriminação racial (Raposo, 2007; Campos \& Vaz, 2013). Como refere o rapper Karlon numa música:

Crioulo para mim é língua mais do que oficial

É um amor materno que nunca me larga (Karlon, Sol na céu, 2018) $)^{25}$.

Símbolo identitário da juventude negra e periférica, o rap crioulo torna-se assim um recurso para afirmarem uma consciência diaspórica distintiva, em que as referências culturais africanas servem de base a um discurso de comunidade. A cumplicidade gerada pelo rap crioulo está expressa na fala do rapper Kromo Di Ghetto:

Quando um gajo começou a expandir o rap crioulo, aí eu encontrei o que faltava, o puro que está no sangue. Português desculpa lá mas... [...] Eu nasci em Portugal e no entanto não me deram nacionalidade portuguesa, sou cabo-verdiano. Desde que eu comecei a perceber como é que o governo, o sistema cá é fodido, eu disse: o quê? Eu agora vou cantar em português ainda por cima para pessoas que não entendem aquilo que um gajo vive, aquilo que um gajo sente, aquilo que uma pessoa pensa, não. Vou cantar em crioulo para aqueles que vivem aqui na zona ou que vive nas mesmas condições em que eu vivo, aí sim eles vão perceber ( Nu bai. $O$ rap negro de Lisboa, 2007).

A vivência em bairros racializados - definidos pelos próprios como guetos - molda decisivamente o rap crioulo em Portugal. Na análise de algumas letras fica evidente a centralidade do território, uma entidade ativa cujos "quadros de interação local" (Costa, 1999: 293) são narrados através das experiências quotidianas de seus autores $^{26}$. Por meio de suas canções, os jovens revelam um profundo sentimento de
25. Tradução livre do crioulo para o português. Ouvir em: $<$ https:// www.youtube. com.watch?v=xPHtuZhD10>.

26. Esta questão remete para o conceito de "extreme local", desenvolvido por Murray Forman (2000), onde o autor enfatiza a importância de referências explícitas aos vários lugares nas músicas rap . 
27. Tradução livre dos autores do crioulo para o português. Ouvir em: $<$ https:// www.youtube.com/ watch?v= bHYZUEPXtcE>.

28. Nem todos os rappers a cantar em crioulo são negros ou têm origem cabo-verdiana, pois esta língua exerce uma forte influência nas sociabilidades dos jovens das periferias de Lisboa independentemente da cor da pele. pertença ao bairro, vivido como pequenos mundos relacionais, em que a busca de identificações positivas sobre essas áreas estigmatizadas caminha lado a lado com um olhar crítico sobre o lugar social que ocupam e as precárias condições de habitabilidade. Muito comum no imaginário do hip-hop, a palavra gueto costuma ser ressignificada pelos rappers para exaltar as qualidades de seus territórios e moradores. Eles subvertem os estereótipos através das crônicas que fazem sobre a vida no gueto, transformando as aprendizagens informais adquiridas nesse ambiente de forte privação num elemento biográfico valorizado (Raposo, 2007). Esta ideia é transmitida por Ne Jah e Euzy no rap abaixo, em que o gueto é a "cultura" onde eles navegam, conferindo "armadura" para amadurecerem enquanto indivíduos no enfrentamento das injustiças.

\author{
Barracada carimbado dentro de mim \\ Será que um dia eu vou deixar de ser eu? \\ Nigga, que me põe a navegar \\ Só o meu gueto é que me põe a navegar \\ Só o meu gueto é que me põe a navegar \\ Guetto é a minha cultura, minha armadura, minha sepultura \\ Lei da rua que eu conheço, foi no gueto que eu estudei \\ Foi no gueto que eu vi como a vida é dura \\ Crioulo é dialeto que dentro do gueto perdura \\ Nos vários tipos de cor, nacionalidade, rua \\ Crioulo é gueto, o gueto é rua que nós todos exploramos e que \\ por ele já choramos \\ É dentro dele que luto para sair desta porra \\ Foi dentro do gueto que nós vivemos, é lá que eu sofro \\ No gueto, mano, eu espero pela minha hora \\ Eu não vivo no gueto, o gueto está dentro de mim [...] \\ Foi aqui na Margem [Sul] que aprendemos a lutar por tudo aquilo \\ que nós amamos \\ Nós somos: Filhos das Barracas! \\ Só o meu gueto é que me põe a navegar \\ Só o meu gueto é que me põe a navegar \\ (Ne Jah ft Euzy, Ghetto, FdiB, 2013)27.
}

Apropriado como marcador social da diferença (Pardue, 2015), o rap crioulo é um dispositivo de afirmação étnico-racial de forte cunho ideológico e político. Ao se conectarem através da língua nativa de seus pais, os jovens participantes desta cultura juvenil ${ }^{28}$ constroem uma comunidade de afetos que frequentemente se converte em processos colaborativos capazes de abrir desde novas oportunidades para os seus projetos musicais a ações coletivas de resistência às injustiças. Neste processo, os jovens estabelecem fluxos inovadores entre os bairros onde vivem e o centro, conferindo centralidade aos seus locais de residência enquanto lócus de criatividade musical e artística, nomeadamente da música rap em Portugal. Nesse 
trânsito entre diferentes mundos, os jovens ampliam o seu capital cultural, tornando-se alguns deles exímios mediadores entre a cidade e as suas margens.

A pedagogia informal levada pela adesão ao rap fomenta um desassossego em relação às injustiças que marcam os seus territórios. Em muitos casos, este sentimento motiva-os a engajarem-se em coletivos informais e associações locais, seja para melhor impulsionar as suas músicas, seja para influenciar os contornos das sociedades desiguais em que vivem. Por isso, importa enquadrar o rap crioulo como uma estética insurgente mobilizadora de um "habitus de resistência" (Crossley, 1999: 649) que serve de rastilho para novos engajamentos políticos e associativos. O caso de Chullage é emblemático disso mesmo, em que a música rap serviu de força motriz tanto para a sua experiência urbana como para a sua conscientização política. Como o próprio explica:

[...] ao ter que cantar aqui e ali, conheces muito mais bairros, conheces muito mais gente. 0 rap aquilo que me fez foi isso, senão eu não conhecia ninguém, tás a ver. Foi mesmo através do rap que eu conheci um mundo de gente. Também foi através da associação [Khapaz]. Eu fiz uma associação, ou me juntei com brothers para fazer uma associação por aquilo que o rap me educou, pela necessidade que eu aprendi com o rap (Chullage, entrevista, 2005).

\section{Circuitos digitais no rap crioulo}

Antes menosprezado pelas editoras, rádios e outros meios de comunicação hegemônicos, o rap crioulo atualmente é um dos estilos musicais mais dinâmicos da juventude portuguesa, mobilizando artistas e uma legião de fãs que se utilizam das novas tecnologias de produção e divulgação para se fazerem visíveis (Campos \& Simões, 2011; Aderaldo \& Raposo, 2016). De fato, o rap crioulo tem conseguido romper com o bloqueio da indústria cultural, conquistando novos espaços sonoros na internet, em rádios comerciais e no espaço público ${ }^{29}$. Este trânsito musical ilustra a crescente importância que as produções artístico-culturais dos jovens desfavorecidos têm vindo a adquirir na atualidade, capaz de conferir-Ihes uma nova visibilidade (Caldeira, 2012). As novas tecnologias e redes digitais cumprem um papel decisivo nesse processo, ao propiciar novos modos de legitimação do consumo e do gosto estético (Marcon, Sedano \& Raposo, 2018). O aparecimento de estúdios caseiros e a posse de dispositivos digitais - samplers, computadores pessoais, softwares de composição musical, websites ou serviços streaming ${ }^{30}$ - são exemplares da maior horizontalidade nas dinâmicas de produção musical (Aderaldo \& Raposo, 2016), redimensionando a importância do rap crioulo na cena artística portuguesa.

29. Embora neste artigo abordemos apenas o contexto português, o rap crioulo também está presente em Cabo Verde e nos Estados Unidos.

30. Destacam-se o FruityLoops (1997); Napster (1999); eMule (2002); Myspace (2003), Facebook (2004); Youtube (2005); Spotify (2008). 
31. Ouvir em: <https://www. youtube.com/ watch?v=

CdwpnmYQ9X8>.

32. Ouvir em: <https://www. youtube.com/ watch?v=uCsjW7em $w E>$.
Inserido num circuito independente e underground que atua à margem das editoras, o rap crioulo passou a ter muitas canções com impacto nas redes digitais. Não por acaso, a música "Tempo antigo" ${ }^{31}$, do artista nascido na Reboleira Apollo G, tem mais de 18 milhões de visualizações no YouTube e a "Sem mimos"32, do rapper da margem sul Ne Jah, mais de quatro milhões. São vários os videoclipes de rap crioulo com mais de um milhão de visualizações no YouTube, website que se tornou um meio de divulgação basilar para os artistas periféricos. Como nos diz Jackson, que vive no bairro da Cova da Moura:

[Com o aparecimento do MySpace] há muita diferença porque depois de meteres o vídeo no YouTube e no MySpace também, são consultas mesmo... São consultas boas mesmo. A diferença antes e depois..., por exemplo, porque antes eu divulgava através do CD. Se queria divulgar para a Holanda, Cabo Verde, Luxemburgo só se eu tivesse lá alguém conhecido, mandava pelo correio, que era para depois dizer: "yah, espalhem lá pelo pessoal". Com a internet não há essa barreira, estás a perceber?, chega a qualquer lado do mundo, seja na França, seja no Japão (Jackson, entrevista, 2011).

A intensificação do poder da imagem e o maior acesso às câmeras digitais, tornaram os videoclipes o principal meio de divulgação do trabalho desses artistas, cujas canções ganham uma visibilidade redobrada a partir de plataformas como o MySpace, YouTube e Instagram. Ao vincularem uma estética insurgente que se utiliza em seus corpos e territórios racializados, eles reinventam uma negritude e africanidade oposta aos discursos de teor lusotropicalista do Estado português que alegorizam as desigualdades e violências que recaem sobre eles. A postura desafiadora com que se exibem a si próprios colide de frente com os discursos institucionais celebradores de uma sociedade portuguesa ontologicamente harmônica e tolerante que higieniza processos de violência passados e presentes (Araújo, 2013). É o que atesta a música "Sr. Agente" de Yuri G, um rapper do bairro da Quinta do Mocho (município de Loures), que denuncia o cotidiano de brutalidade policial enfrentada pela juventude negra dos bairros periféricos:

Sr. Agente: Para, para, para! Eles não gostam de nós

Eles não gostam de nós

Que se foda o mundo, que se foda tudo

Sr. agente eu sou um miúdo

Eu nasci num mundo vagabundo

Aquele miúdo é inocente, tudo [o resto] é culpado [...]

[Polícia] Dispara a sua arma na cara do puto [...]

[Polícia] tem gana de matar o puto que está na sua frente

Porque para si a sua dor é indiferente

Isto é, fucking racismo dentro da sua mente 
Não o faz sentir diferente

Eu estou farto do nome "Agente"

Sinceramente, onde está a força dos manos unidos

Que é para a acabar com o abuso violento

Aqueles homens de farda querem patente

Soltar ou matar isso [para eles] é indiferente

Não te dão nenhum valor, cospem para a frente

Postura de homem, nós somos combatentes

Estamos fartos de abuso no nosso presente

(Yuri G, Sr Agente, 2018) ${ }^{33}$.

O videoclipe desta música simula o assassinato de um jovem negro da Quinta do Mocho por um agente policial, ao mesmo tempo em que se alternam imagens do rapper a cantar algemado e de jovens a manifestarem-se com cartazes contra o racismo e a violência policial. Também vemos uma atitude de resistência no videoclipe "Sem mimos", em que crianças e jovens encenam as dificuldades de viverem num ambiente predatório marcado pela ausência de carinho e oportunidades. Mesmo no videoclipe "Tempo antigo", cujo mote é a celebração da infância, amizade e vida no gueto, encontram-se elementos de oposição em relação ao estado de exceção que caracteriza os seus territórios, nomeadamente quando um camburão da polícia atravessa o bairro e, em êxtase coletivo, os jovens cantam o refrão a uma só voz "contra" as autoridades.

Os videoclipes do rap crioulo prolongam toda uma tradição de produção musical, através de mixtapes caseiras (em cassetes e CDs) pontuadas por narrativas de denúncia das injustiças da sociedade portuguesa, agora atualizando o reportório estético, aliando o som à imagem ${ }^{34}$. Nas mensagens desses videoclipes, vincula-se uma estética insurgente que não apenas põe em pauta as reivindicações das populações afrodescendentes, mas a sua própria legitimidade de existirem enquanto cidadãos íntegros em Portugal. Com ironia ou por via de uma postura mais combativa, os videoclipes ajudam a visibilizar as reivindicações da juventude pobre, negra e periférica, uma das populações historicamente alijadas do direito à palavra em Portugal.

\section{Considerações finais}

Ao cumprir um papel efetivo no descortinar de realidades até então desconhecidas, os rappers negros das periferias de Lisboa foram alguns dos responsáveis por colocar os temas do racismo e da negritude na ordem do dia em Portugal, nomeadamente os que cantam em crioulo. Até hoje eles desempenham um papel ativo na luta antirracista no país, seja participando de manifestações e shows contra o racismo, seja integrando coletivos e associações do movimento negro. A língua, a
33. Tradução livre dos autores do crioulo para o português. Ouvir em: <https://www. youtube.com/ watch?v=

JCaxcf3BTxE>

34. Não obstante a importância desses videoclipes enquanto meio de verbalizar (e difundir) mensagens e experiências da juventude negra em Portugal, a comercialização de CDs e,

principalmente, a troca informal de canções de rap através da Internet e de novos dispositivos digitais (telemóveis, leitores de MP3), assumem uma importância significativa no modo como o "subalternizado fala" para o mundo (Spivak, 2010). 
35. Diferente do sentido dado por Benedict Anderson (1983), especificamente voltado à problemática da formação do Estado-nação, a ideia de "comunidade imaginada" em tela quer chamar a atenção para o discurso de comunidade e o sentido de identidade coletiva advinda de origens sociais, geográficas e étnico-raciais comuns.

36. Muitos deles aprenderam a utilizar complexos recursos digitais, seja para fazerem videoclipes e produzirem as suas músicas, seja para as divulgarem com vista a comercialização (Aderaldo \& Raposo, 2016).

37. Vários artistas do rap crioulo de Portugal são conhecidos na diáspora caboverdiana, realizando concertos em França, Luxemburgo ou Reino Unido, para além de Cabo Verde. origem étnico-racial, a crítica ao estatuto de subalternidade, a afirmação da negritude e africanidade, bem como a valorização dos territórios estigmatizados em que vivem são algumas das especificidades que conferem unidade ao rap crioulo, contribuindo para moldar uma "comunidade imaginada" (Anderson, 1983) ) $^{35}$ entre os participantes que não se restringe à juventude de origem cabo-verdiana.

Espaço de sociabilidade e formação subjetiva, o rap crioulo fomenta um conjunto de experiências que ultrapassam a música, ao ampliar o conhecimento diaspórico dos jovens sobre a história, a cultura e a política em que estão imersos, além de incentivar aprendizagens informais no campo das novas tecnologias ${ }^{36}$. A utilização de dispositivos e redes digitais para visibilizarem sua presença histórica no país tornou-se um meio privilegiado para falarem - e cantarem - ao mundo, quando denunciam relações de poder desiguais estruturadas pelo racismo e por formas renovadas de colonialidade. Desta forma, a postura de resistência que subjaz a este estilo musical oferece uma forma de enxergar a realidade e de se comportar geradora de uma consciência crítica que traz à baila uma visão política sobre o seu lugar na sociedade.

Os shows que realizam nos bairros da periferia e no centro de Lisboa, bem como os videoclipes divulgados na internet, são algumas das estratégias desses artistas para se tornarem reconhecidos e valorizados no espaço citadino, transmitindo saberes a partir de lugares sociais à margem do poder e numa perspectiva decolonial, no sentido que Mignolo (2007) dá ao termo. A partir das novas tecnologias digitais o rap crioulo ampliou as possibilidades de trocas entre aqueles que partilham os símbolos dessa cultura urbana, bem como de uma identidade negra e periférica, o que permitiu a sua expansão às redes nacionais e transnacionais ${ }^{37}$. Ao criticar os discursos estereotipados que pesam sobre eles e os seus bairros, os rappers problematizam a situação de marginalização de suas vidas, reinventando-se enquanto jovens negros. Nesse processo, entram em choque direto com os projetos de cidadania de base lusotropicalista e multicultural, pois não escondem o racismo e as injustiças que subjazem às suas difíceis condições de vida.

O poder estético e político do rap crioulo transformou-o em uma das potentes linguagens de resistência da juventude negra em Portugal. Frente a instituições insensíveis aos seus anseios e interesses, este estilo musical é um instrumento privilegiado na projeção de uma visibilidade que a representa como potência, desenvolvendo uma estética insurgente que a encoraja a construir novos horizontes de justiça social. 


\section{Referências}

ABRANTES, Pedro; ROLDÃO, Cristina. Old and new faces of segregation of Afro-descendant population in the Portuguese education system: a case of institutional racism? Conferência educação comparada para além dos números: contextos locais, realidades nacionais e processos. Lisboa: Universidade Lusófona, 2016

ADERALDO, Guilhermo; RAPOSO, Otávio. Deslocando fronteiras. Notas sobre intervenções estéticas, economia cultural e mobilidade juvenil em áreas periféricas de São Paulo e Lisboa. Horizontes Antropológicos, v. 22, n.45, p. 279-305, 2016.

AGIER, Michel. Distúrbios Identitários em tempos de globalização. Mana, v. 7, n. 2, p. 7-33, Rio de Janeiro, 2001.

AMNISTIA INTERNACIONAL. Amnesty International Report 2017/2018: The State of The World's Human Rights. 2018. Disponível em: <https://www.amnesty.org/en/countries/europe-and-central-asia/portugal/report-portugal/. Acessado em: 22 Jun. 2020.

ANDERSON, Benedict. Imagined communities: reflections on the origin and spread of nationalisms. London: Verso, 1983.

ARAÚJO, Marta. Challenging narratives on diversity and immigration in Portugal: the (de)politicization of colonialism and racism. In: KRETSEDEMAS, P. (Org.). Migrant marginality: a transnational perspective, p. 27-46. Oxfordshire, UK: Routledge, 2013.

ARAÚJO, Marta; MAESO, Silvia. Os contornos do eurocentrismo: raça, história e textos políticos. Coimbra: CES; Almedina, 2016.

BENNETT, Andy. Popular music and youth culture: music, identity and place. London: Macmillan, 2000.

CALDEIRA, Teresa. Inscrição e circulação: novas visibilidades e configurações do espaço público em São Paulo. Novos Estudos Ceb rap , n. 94, p. 31-67, 2012.

CAMPOS, Ricardo. Juventude e culturas de rua híbridas. Sociologia \& Antropologia, v. 10, n. 2, Maio-Ago. 2020.

CAMPOS, Ricardo; SIMÕES, José Alberto. Participação e inclusão digital nas margens: uma abordagem exploratória das práticas de culturais de jovens afro-descendentes. O caso do rap negro. Media \& Jornalismo, n. 19, p. 117-133, 2011.

CAMPOS, Ricardo; VAZ, Cláudia. Rap e graffiti na Kova da Moura como mecanismos de reflexão identitária de jovens afrodescendentes. Sociedade e Cultura, v. 16, n. 1, p. 127-139, 2013. 
CONTADOR, António. Cultura juvenil negra em Portugal. Oeiras, PT: Celta Editora, 2001. COSTA, António Firmino da. Sociedade de bairro. Dinâmicas sociais da identidade cultural. Oeiras, PT: Celta Editora, 1999.

CROSSLEY, N. Fish, field, habitus and madness: the first wave mental health users movement in Great Britan. British Journal of Sociology, v. 50, n. 4, p 647-670, 1999.

DAYRELL, Juarez. A música entra em cena. O rap e o funk na socialização da juventude. Belo Horizonte: Editora UFMG, 2005.

NU BAU. O RAP NEGRO DE LISBOA, documentário de Otávio Raposo, 2007. Disponível em: <https://www.youtube.com/watch?v=MvYlcg3o7-w>.

DUARTE, Mariana. Guerreira do rap. Jornal Público, 27 Fev. 2018. Disponível em: <https://www.publico.pt/2018/02/27/culturaipsilon/noticia/mynda-guevara rap -acima-de-tudo--e-feito-por-mulheres-1804454>. Acesso em: 02 Abr. 2019.

COMISSÃO EUROPEIA CONTRA O RACISMO E A INTOLERÂNCIA (ECRI). Relatório da Ecri sobre Portugal (quinto ciclo de controlo). Strasbourg: Conselho da Europa, 2018. Disponível em: <https://rm.coe.int/fifth-report-on-portugal-portuguese-translation-/16808de7db>. Acesso em: 22.06.2020

FORMAN, Murray. "Represent": race, space and place in rap music. Popular Music, v. 19, n. 1, p. 65-90, 2000.

FRADIQUE, Teresa. Fixar o movimento: representações da música rap em Portugal. Lisboa: Dom Quixote, 2003.

GOLDBERG, David Theo. The racial state. Malden; Oxford; Victoria: Blackwell Publishers, 2002.

HODKINSON, Paul. Translocal connections in goth scene. In: BENNETT A.; PETERSON R. (Orgs.). Music scenes. Local, translocal, and virtual, p. 131-148. Nashville, TN: Vanderbilt University Press, 2004.

HUQ, Rupa. Beyond subculture: pop, youth and identity in a postcolonial world. London: Routledge, 2006.

JORNAL GUETO. Editorial: Olhos, ouvidos e vozes. n. 0, 2007.

KEYES, Cheryl L. rap music and street consciousness. Chicago, IL: University of Illinois Press, 2004. 
KITWANA, Bakari. The challenge of rap music from cultural movement to political power. In: FORMAN M.; NEAL, M. A. (Orgs.). That's the joint! The hip-hop studies reader, p. 341-350. London; New York: Routledge, 2004 [2002].

LAHON, Didier. O escravo africano na vida económica e social portuguesa do antigo regime. Africana Studia, n. 7, p. 73-100, Porto, 2004.

LIPSITZ, George. We know what time it is: race, class and youth culture in the nineties. In: ROSS, A.; ROSE, T. (Orgs.). Microphone fiends: youth, music and culture, p. 17-28. London; New York: Routledge, 1994.

MACEDO, Márcio. Hip-hop SP: transformações entre uma cultura de rua, negra e periférica. In: KOWARICK, L.; FRÚGOLI, J. H. (Orgs.). Pluralidade urbana em São Paulo: vulnerabilidades, marginalidade, ativismos, p. 23-54. São Paulo: Editora 34, 2015.

MARCON, Frank; SEDANO, Livia Jiménez; RAPOSO, Otávio. Introdução ao dossiê: Juventudes e Músicas Digitais. Cadernos de Arte e Antropologia, v. 7, n. 1, p. 5-14, 2018.

MIGNOLO, Walter D. Introduction: coloniality of power and de-colonial thinking. Cultural Studies, v. 21, n. 2-3, p. 151-167, 2007.

MITCHELL, Tony. Introduction: Another root - hip hop outside the USA. In: MITCHELL T. (Org.). Global noise: rap and hip-hop outside the USA. Middletown, CT: Connecticut, Wesleyan University Press, 2001, p. 1-38.

NEAL, Mark Anthony. The message: rap, politics, and resistance. In: FORMAN, M.; NEAL, M. A. (Orgs.) That's the joint! The hip-hop studies reader, p. 307-309. London; New York: Routledge, 2004.

OLIVEIRA, Catarina Reis; GOMES, Natália. Indicadores de integração de imigrantes: Relatório estatístico anual 2017. Lisboa: Alto Comissariado para as Migrações, 2017.

PARDUE, Derek. Cape Verde, let's go: creole rappers and citizenship in Portugal, Chicago, IL: University of Illinois Press, 2015.

Brazilian hip-hoppers speak from the margins. Houndmills, UK: Palgrave Macmillan. 2011.

PERKINS, William Eric. The rap attack: an introduction. In: (Org.). Droppin' science: critical essays on rap music and hip hop culture, p. 1-45. Filadélfia, PA: Temple University Press, 1996. 
RAPOSO, Otávio. Arte e cultura: aprendizagens informais na Afro-Lisboa. Mediações. Revista On-line da Escola Superior de Educação, v. 7, n. 2, p. 37-52, 2019.

. "Tu és rapper, representa arrentela, és red eyes gang". Sociabilidades e estilos de vida de jovens do subúrbio de Lisboa. Sociologia, Problemas e Práticas, n. 64, p.127-147, 2010.

Representa red eyes gang: das redes de amizade ao hip hop. Dissertação (Mestrado em Antropologia Urbana) - Instituto Universitário de Lisboa (ISCTE-IUL), Lisboa, 2007.

Sociabilidades juvenis em contexto urbano. Um olhar sobre alguns jovens do Bairro Alto da Cova da Moura. Revista Fórum Sociológico, n. 13/14, p. 151-170, 2005

RAPOSO, Otávio; SEDANO, Livia Jiménez; LIMA, Redy Wilson. Introdução ao dossiê juventudes, decolonialidades e estéticas insurgentes. Revista Tomo, n. 37, Jul./Dez, 2020.

RAPOSO, Otávio, ALVES, Ana Rita; VARELA, Pedro; ROLDÃO, Cristina. Negro drama. Racismo, segregação e violência policial nas periferias de Lisboa. Revista Crítica de Ciências Sociais, n. 119, p. 5-28, 2019.

ROSE, Tricia. Black noise: rap music and black culture in contemporary America. London: Wesleyan University Press, 1994.

SAUCIER, P. Khalil. Native tongues. An African hip-hop reader. Trenton, NJ: Africa World Press, 2011.

SERVIÇO DE ESTRANGEIROS E FRONTEITAS (SEF). Relatório de imigração, fronteiras e asilos 2019. 2019. Disponível em: <https://www.sef.pt/pt/pages/conteudo-detaIhe.aspx?nID=92>. Acesso em: 25 Jun. 2011.

SIMÕES, José Alberto. Entre percursos e discursos identitário: etnicidade, classe e gênero na cultura hip-hop. Revista de Estudos Feministas, v. 21, n. 1, p. 107-128, 2013.

Entre a rua e a internet. Um estudo sobre o hip-hop português. Lisboa: Imprensa de Ciências Sociais, 2010.

SIMÕES, José Alberto; CAMPOS, Ricardo. Digital media, subcultural activity and youth participation: the cases of protest rap and graffiti in Portugal. Journal of Youth Studies, v. 20, n.1, p. 16-31, 2017. 
SIMÕES, José Alberto; NUNES, Pedro \& CAMPOS, Ricardo. Entre subculturas e neotribos: propostas de análise dos circuitos culturais juvenis. O caso da música rap e do hip-hop em Portugal. Fórum Sociológico, n. 13-14 (2ª série), p. 171-189, 2001.

SIMÕES, Soraia. Fixar o (in)visível: papéis e reportórios de luta dos dois primeiros grupos de rap femininos a gravar em Portugal (1989-1998). Cadernos de Arte e Antropologia, v. 7, n. 1, p. 97-114, 2018.

. RAPublicar: A micro-história que fez história numa Lisboa adiada. Lisboa: Caleidoscópio, 2017.

SPIVAK, Gayatri Chakravorty. Pode o subalterno falar? Belo Horizonte: Editora UMG, 2010.

VALE DE ALMEIDA, Miguel. Um mar da cor da terra: raça, cultura e política da identidade. Oeiras, PT: Celta Editora, 2000.

VARELA, Pedro; RAPOSO, Otávio; FERRO, Lígia. Redes de sociabilidade, identidades e trocas geracionais: da "Cova da Música" ao circuito musical africano da Amadora. Revista Sociologia, Problemas e Práticas, n. 86, p. 109-132, 2018.

WELLER, Wivian. A construção de identidades através do hip hop: uma análise comparativa entre rappers negros em São Paulo e rappers turcos-alemães em Berlim. Caderno CRH, n. 32, p. 213-232, Jan./Jun. 2000.

WHYTE, William Foote. Sociedade de esquina: a estrutura social de uma área urbana pobre e degradada. Rio de Janeiro: Jorge Zahar, 2005 [1943].

WOODS, Orlando. The digital subversion of urban space: power, performance and grime. Social \& Cultural Geography, v. 21, n. 3, p. 293-313, 2020.

YÚDICE, George. Nuevas tecnologías, música y experiencia. Barcelona: Gedisa Editorial, 2007. 
